\title{
Ontology-Based Operational Risk Identification in 3PL
}

\author{
J.C. Osorio ${ }^{1}$, D.F. Manotas ${ }^{1}$, J.L. García ${ }^{2}$ \\ ${ }^{1}$ Escuela de Ingeniería Industrial, Universidad del Valle, Cali, \\ Colombia \\ ${ }^{2}$ Universidad Autónoma de Ciudad Juárez, \\ Departamento de Ingeniería Industrial y Manufactura, \\ México \\ \{juan.osorio, diego.manotas\}@ correounivalle.edu.co,jorge.garcia@uacj.mx
}

\begin{abstract}
Supply chain risk management is an important activity in current supply chain management, and operational risk is one of the most important risks in supply chains. The risk identification process is one of the most important activities in supply chain risk management system. The participation of Third Party Logistics providers (3PL) in supply chains has been increasing, and it is important to consider how their presence affects risk management. On the other hand, ontologies define a common vocabulary to share information in a domain. Considering all these aspects, we propose an ontology approach to operational risk identification in supply chain that involves third party logistics providers. The ontology-based approach is oriented to improve communications about risks through the whole supply chain, achieving better results in risks management activities. The approach is validated in ground transportation activities.
\end{abstract}

Keywords: supply chain risk management, operational risk, third party logistics, ontology, ground transportation.

\section{$1 \quad$ Introduction}

Supply Chain Risk Management (SCRM) has become in one of the more important activities into de Supply Chain Management (SCM), and according with [2] SCRM has emerged as an important research subject in the field of SCM. SCRM has also taken on an increased importance for firms, particularly as global sourcing has increased, companies have "leaned out" their supply chains (SC), and product cycle times have become shorter [5]. The recent trend of focusing on core competence has also contributed to the popularity of logistics outsourcing and the participation in supply chain the third party logistics companies (3PL). According to this trend and its role for the success of SC, it is important to consider that the participation of 3PL providers modifies the traditional structures of supply chains, where 3PL providers become the new links and new risks arise or their probabilities or impacts change. 
SCRM consist in four components [7, 14]: risk identification, risk prioritization and evaluation, risk management and risk monitoring, and some authors are agree that the success of SCRM resides mainly in the first two steps.

The identification of operational risks is the fundamental step in risk management. According to [14], qualitative techniques are used the most, and they rely on the knowledge and expertise of the experts involved. But considering this, it is necessary to have a unified language that allows sharing information throughout the chain. Sharing risk is a fundamental activity oriented to achievement an effective SCRM.

Operational risk is one of the most important risks in SC. Operational risks refer to the inherent uncertainties in day-to-day operations, such as the uncertainty in consumer demand, uncertainty in supply and uncertainty of costs.

"An ontology defines the basic terms and relations that compose the dictionary of the field of interest and the rules that combine the terms and relations so that the dictionary of terms is extended" [13].

In this paper we propose an ontology based approach to operational risk identification in supply chain that consider 3PL companies. Our proposal is oriented to improve both, risk identification activities and sharing information about risk among the whole supply chain.

\section{$2 \quad$ Literature Review}

\subsection{Supply Chain Risk Management (SCRM)}

Risk management in the supply chain refers to the concept of Supply Chain Risk Management (SCRM), which would be beneficial to the parties involved in terms of cost reduction and increase in profitability [10]. Management of risks is becoming the focal concern of the firms to survive in a competitive business environment. Thus SCRM has emerged as a natural extension of supply chain management with the objective of identifying the potential sources of risks and proposing appropriate action plans to mitigate them. But elaborating an effective SCRM program is a critical task and requires abilities in multiple areas [25].

Considering these it is clear that managing the risks present in the supply chain is an activity that requires the interest and effort of organizations looking to keep their position in the market [14].

An effective system for supply chain risk management has to identify, evaluate and quantify risks in such a way that the organization is able to generate its plans depending on the risks that have the greatest impact on their corporate objectives [19].

A risk management system has four clearly defined phases: Identification, evaluation and prioritization, management, and finally monitoring. According to some authors the first two phases are critical for the success of the system, and the definition of priorities becomes definitive when deciding on the actions required for the identified risks to be mitigated or eliminated [20].

\subsection{Operational Risk Management}

Although the proper definition of operational risk has often been the subject of past heated debate there is general agreement among risk professionals that the definition 
should, at a minimum, include breakdowns or failures relating to people, internal processes, technology or the consequences of external events [28].

Operational risks abound in every sector of the economy and in every human endeavor. Operational risks are found much sectors and in all activities [28]. Operational risks include most of what can cause an organization harm, that is foreseeable and, to a very large extent, avoidable - if not the events themselves, then at least their impact on the organization [28].

Risk is a measure of random fluctuations in performance through time. Operational risk measures the connection between those performance fluctuations and business activities [18]. Operational risks are foreseeable, and to some measure, avoidable (if not the adverse event, at least its consequences on the organization). It is clear that operational risks might be mitigated only after they have been correctly identified. A risk that has been correctly identified is no longer a risk; it becomes a management problem [20]. That is one of the most important reasons for work in risk identification.

\subsection{Risk identification}

The first step of risk management is to identify the sources or drivers of risks. Enterprises need to collect all possible threats systematically. The risks can be found in different aspects, either from external environment or internal operations. In logistics chains, the chance of exposure to risk is higher than other departments [27].

In order to manage and control risk effectively, management needs a clear and detailed picture of the risk and control environment in which they operate. Without this knowledge, appropriate action cannot be taken to deal with rising problems. For this purpose, risks must be identified. This includes the sources, the events and the consequences of the risks [28].

Risk identification involves a comprehensive and structured determination of potential SC risks associated with the given problem [26]. Also risk identification should include consideration of the side effects of particular consequences. A wide range of consequences should also be considered even if the source of the risk or its cause may not be evident [7].

\subsection{Third Party Logistics (3PL)}

The growing need of companies to focus on the core object of their business has originated a trend towards outsourcing different activities. The activities of the supply chain have evolved from a first stage with companies responsible for their own logistical processes, to companies delegating all their logistical activities to specialized agents [14].

Successful supply chains need successful logistics, and the contemporary role of the third party logistics (3PL) has moved from simple out tasking to full outsourcing. 3PLs are not just supply chain service providers; they are now supply chain strategy partners. 3PLs work simultaneously with multiple supply chain partners [9].

The role of logistics services is very critical to conduct the smooth flow of materials and information in forward and reverse supply chain.

According to this trend and its importance for the success of supply chains, it is important to consider that the participation of 3PL providers modifies the traditional structures of supply chains, where 3PL providers become the new links and new risks 
arise or their probabilities or impacts change [24]. And, according to the results of the third party logistics study the most frequently outsourced activities are domestic transportation (86\%), warehousing $(66 \%)$, international transportation $(60 \%)$, freight forwarding (44\%) and customs brokerage (42\%) [11]. For this reason, the proposal in this paper focuses in the transporting activities in the supply chain.

\subsection{Ontologies}

"An ontology defines a common vocabulary for researchers who need to share information in a domain. It includes machine-interpretable definitions of basic concepts in the domain and relations among them. Why would someone want to develop an ontology? Some of the reasons are: To share common understanding of the structure of information among people or software agents. To enable reuse of domain knowledge. To make domain assumptions explicit. To separate domain knowledge from the operational knowledge. And, to analyze domain knowledge" [18].

An ontology is a general conceptualization of a specific domain in both human and machine readable format [13]. Ontologies can be used as a backbone for the integration of expert knowledge and the formalization of project results, including advanced predictive analytics and intelligent access to third party data, through the integration of semantic technologies [12]. Ontology has different meanings according to the community in which the concept is defined. However, in a general point of view, an ontology is used to formally describe the "nature and structure of things" in terms of categories and relationships[24].

There are some papers where using ontologies for risk management like $[1,3,6,8$, $13,15-17,21-23$ ] but any of them are applied in operational risk management in third party logistics activities.

\section{Methodology}

According with some authors, there is not a single way to developing ontologies, but they agree with several points that must consider in the ontology design. These points are $[4,13,18]$ :

- Determine the domain and scope of the ontology: that is, answer basic questions like this:

What is the domain that the ontology will cover? It is important to know which objects are interesting for the model and which ones not.

For what we are going to use the ontology? The same domain could be modeled with different classes according to the final objective of the ontology.

For what types of questions the information in the ontology should provide answers? To help to domain delimitation and consider the user's point of view in the modeling process.

Who will use and maintain the ontology? It is important to know if the in charge person know about the domain or only introducing instances. 
- Consider reusing existing ontologies: Many ontologies are already available in electronic form and can be imported into an ontology-development environment that you are using [18].

- Enumerate important terms in the ontology: It is useful to write a list of all terms that we will use in the ontology. What are the terms we would like to talk about? What properties do those terms have? What would we like to say about those terms? [18].

- Define the classes and the class hierarchy: this step is one of the most important in the process of developing ontologies [4]. There are several approaches in developing a class hierarchy: top-down, bottom-up and a combination of them [18].

- Define the properties of classes - slots: Once we have defined some of the classes, we must describe the internal structure of concepts. We have already selected classes from the list of terms we created in Step 3. Most of the remaining terms are likely to be properties of these classes [18].

- Define the facets of the slots: Slots can have different facets describing the value type, allowed values, the number of the values (cardinality), and other features of the values the slot can take[18].

- Create instances: The last step is creating individual instances of classes in the hierarchy. Defining an individual instance of a class requires (1) choosing a class, (2) creating an individual instance of that class, and (3) filling in the slot values [18].

\section{$4 \quad$ Results}

Following the proposed methodology, these are the results for our ontology:

- Determine the domain and scope of the ontology.

What is the domain that the ontology will cover? Operational risk management in supply chain with third party suppliers in the chain.

For what we are going to use the ontology? For risk management, especially for risk identification and assessment.

For what types of questions the information in the ontology should provide answers? Types of risks, likelihood and impact, managerial strategies for risks types, echelons in the chain.

Who will use and maintain the ontology? Companies into the supply chain (all echelons in the supply chain with third party logistics providers)

- Consider reusing existing ontologies: according to the literature review, does not exists ontologies in the operational risk domain that can answer the questions presented above. 

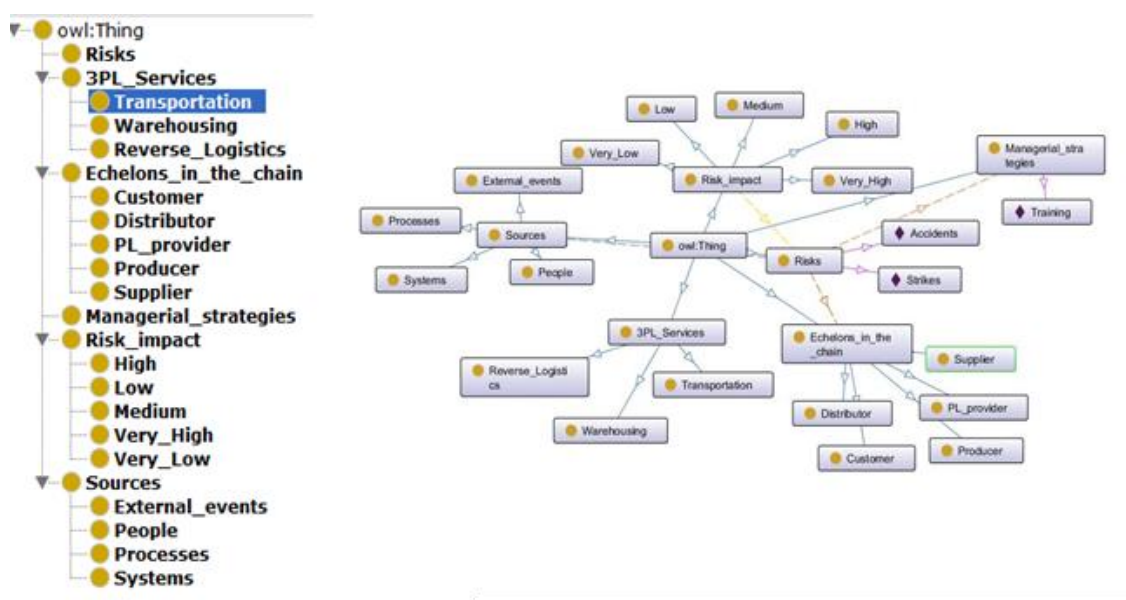

Fig.1. Ontology Classes and Class Hierarchy.

- Enumerate important terms in the ontology: Echelons in the chain, 3PL services, Risks, Resources, Risk impact in the strategical objectives, Management strategies.

- Define the classes and the class hierarchy: Figure 1 shows the classes and the class hierarchy proposed.

- Define the properties of classes - slots: belongsTo3PLServices (relationship between Risk and 3PL Services); hasRisk (relationship between 3PL Services and Risks); hasRiskImpact (relationship between Risks and Risk Impact); IsCausedFor (relationship between Risks and sources); hasManagerialStrategies (relationship between Risks and Managerial strategies); ItOccursBetween (relationship between Risks and Echelons in the chain).

- Define the facets of the slots: in Figure 2 we show the object properties of the proposed ontology.

- Create instances: we created some instances; particularly refer to some risks in transporting activities, such as: accidents, theft, shipping errors, strikes and driver's lack of skills. These risks have different impact and source as show in table 1.

We hope to use the ontology in a web application that allows all echelons in the chain to share the information to improve the processes: risk identification, risk evaluation and risk management.

The idea is to expand the ontology for all 3PL activities such as warehousing, reverse logistics, picking, packing etc. And that consider different transportation modes such as maritime transportation and air transportation.

\section{Conclusions}

We have presented an ontology developed to improve the operational risk management in supply chain with third party logistics providers, considering that risk identification 


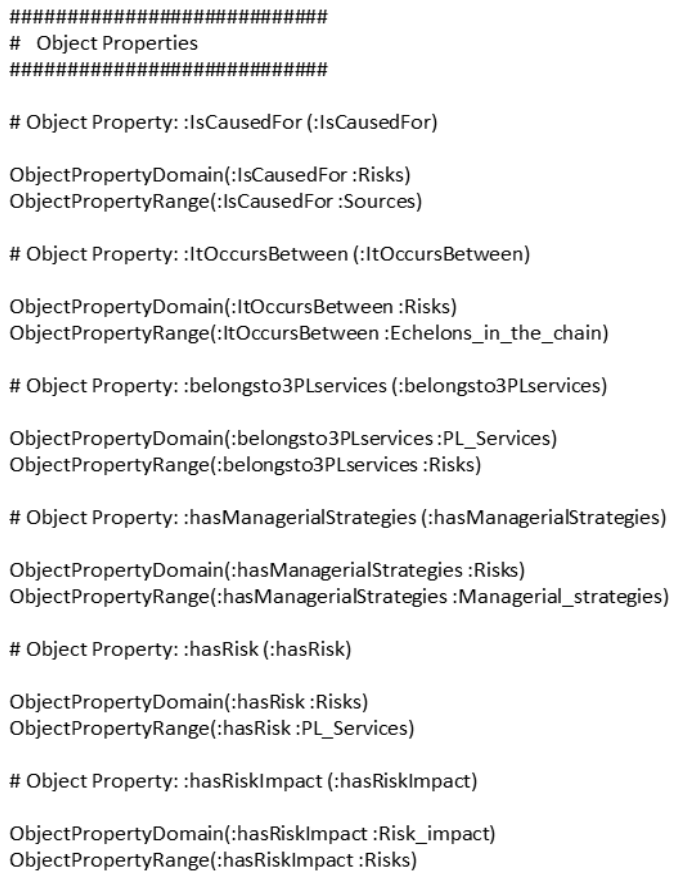

Fig. 2. Object properties (Operational risk ontology).

Table 1. Instances summary.

\begin{tabular}{|c|c|c|c|c|c|}
\hline Risks & $\begin{array}{c}\text { Belongsto 3PL } \\
\text { Services }\end{array}$ & $\begin{array}{c}\text { hasRisk } \\
\text { impact }\end{array}$ & IsCausedFor & $\begin{array}{c}\text { It_Occurs } \\
\text { Between }\end{array}$ & $\begin{array}{c}\text { Managerial } \\
\text { strategies }\end{array}$ \\
\hline Theft & \multirow{4}{*}{ Transportation } & High & $\begin{array}{c}\text { External } \\
\text { events }\end{array}$ & & $\begin{array}{l}\text { Insurance } \\
\text { polices }\end{array}$ \\
\hline $\begin{array}{c}\text { Shipping } \\
\text { errors }\end{array}$ & & Medium & Processes & Distributor & New process \\
\hline Strikes & & Low & $\begin{array}{l}\text { External } \\
\text { events }\end{array}$ & & $\begin{array}{l}\text { Alternative } \\
\text { fleet }\end{array}$ \\
\hline $\begin{array}{c}\text { Driver's } \\
\text { lack of } \\
\text { skills }\end{array}$ & & Low & People & Customer & Training \\
\hline
\end{tabular}

is one of the most important activities in supply chain risk management and with the proposed ontology we hope to promote sharing information about risk throughout the chain.

Although this ontology is developed to operational risk identification process, we hope in the future to involve all the operational risk management system: risk identification, risk evaluation, risk management and risk monitoring in the whole chain.

There are some papers in literature that using ontologies in risk management, but we don't find papers using ontologies for operational risk identification in 3PL services. 


\section{References}

1. Aleksy, M., Seedorf, S., Cuske, C.: A Distributed Simulation Environment for Simulation Modeling in Operational Risk Management. In: International Conference on Complex, Intelligent and Software Intensive Systems, CISIS'08, pp. 126-131 (2008)

2. Aqlan, F., Lam, S. S.: A fuzzy-based integrated framework for supply chain risk assessment. Int. J. Prod. Econ. 161, pp. 54-63 (2015)

3. Atkinson, C., Cuske, C., Dickopp, T.: Concepts for an ontology-centric technology risk management architecture in the banking industry. In: 10th IEEE Int. Enterp. Distrib. Object Comput. Conf. Work. EDOCW’06, pp. 1-7 (2006)

4. Contreras, J., Comeche, J.: Tutorial Ontologías. Madrid Univ. Complut. Madrid (2007)

5. Curkovic, S., Scannell, T., Wagner, B.: Managing Supply Chain Risk. Integrating with Risk Management. CRC Press (2016)

6. Cuske, C., Dickopp, T., Seedorf, S.: JOntoRisk: An ontology-based platform for knowledge-based simulation modeling in financial risk management. (2005)

7. Elmsalmi, M., Hachicha, W.: Risks prioritization in global supply networks using MICMAC method: A real case study. In: Int. Conf. Adv. Logist. Transp. ICALT’13. pp. 394-399 (2013)

8. Elnagdy, S. A., Qiu, M., Gai, K.: Cyber Incident Classifications Using Ontology-Based Knowledge Representation for Cybersecurity Insurance in Financial Industry. IEEE Int. Conf. Cyber Secur. In: Cloud Comput. CSCloud, 2nd IEEE Int. Conf. Scalable Smart Cloud, SSC'16, pp. 301-306 (2016)

9. Kumar, P., Singh, R. K.: A fuzzy AHP and TOPSIS methodology to evaluate 3PL in a supply chain. J. Model. Manag. 7(3), pp. 287-303 (2012)

10. Lam, H. Y.: A knowledge-based logistics operations planning system for mitigating risk in warehouse order ful fi llment. Int. J. Production Economics, pp. 1-17 (2015)

11. Langley, J., Consulting, C.: Third-Party Logistics Study: The State of Logistics Outsourcing. (2017)

12. Leibold, C., Krieger, U. H., Spies, M.: Ontology-based modelling and reasoning in operational risks. In: Kenett Ron; Yossi Raanan. (ed.) Operational Risk Management, A practical approach to intelligent data analysis, pp. 327, Wiley (2011)

13. Lykourentzou, I., Papadaki, K., Kalliakmanis, A., Djaghloul, Y.: Thibaud Latour.: Ontology-based Operational Risk Management. In: IEEE 13th Conf. Commer. Enterp. Comput., pp. 153-160 (2011)

14. Manotas-Duque. D. F., Osorio-Gómez, J. C., Rivera, L.: Operational Risk Management in Third Party Logistics (3PL). In: Alor-Hernández, G. et al. (eds.) Handbook of Research on Managerial Strategies for Achieving Optimal Performance in Industrial Processes (2016)

15. Marques, R. P., Santos, H., Santos, C.: An enterprise ontology-based database for continuous monitoring application. In: IEEE Int. Conf. Bus. Informatics, IEEE CBI'13, pp. 7-12 (2013)

16. Mohammad, M. A., Kaloskampis, I., Hicks, Y. A., Setchi, R.: Ontology-based framework for risk assessment in road scenes using videos. Procedia Comput. Sci. 60(1), pp. 1532$1541(2015)$

17. Nota, G., Rossella, A., Di Gregorio, M. P.: Ontology Based Risk Management. In: Faggini, M., Vinci, C. P. (eds.) Decision theory and choices: A complexity approach, pp. 252, Springer-Verlag (2010)

18. Noy, N. F., McGuinness, D. L.: Ontology Development 101: A Guide to Creating Your First Ontology. Stanford Knowl. Syst. Lab. 25 (2001)

19. Osorio-Gómez, J. C., Manotas-Duque, D. F., Rivera, L., García-Alcaraz, J. L.: Decision Support System for Operational Risk Management in Supply Chain with 3PL Providers. In: Alor-hernández, G., Valencia-García, R. (eds.), Current Trends on Knowledge-Based Systems, pp. 302 (2017) 
20. Osorio-Gómez, J. C., Manotas-Duque, D. F., Rivera-Cadavid, L., Canales-Valdiviezo, I.: Operational Risk Prioritization in Supply Chain with 3PL Using Fuzzy-QFD. In: Garcíaalcaraz, J. L. (eds.), New Perspectives on Applied Industrial Tools and Techniques, pp. 530 (2017)

21. Peng, G. C., Nunes, J. M. B.: Surfacing ERP exploitation risks through a risk ontology. Ind. Manag. Data Syst. 109(7), pp. 926-942 (2009)

22. Polizel, F., Casare, S., Sichman, J.: OntoBacen: A modular ontology for risk management in the Brazilian financial system. CEUR Workshop Proc. 1517 (2015)

23. Robin, C., Uma, G.: Design and Development of Ontology for Risk Management in Software Project Management. In: Proc. Int. Symp, pp. 253-257 (2009)

24. Rodriguez-Elias, O. M., Velázquez-Mendoza, M. J., Rose-Gómez, C. E.: An Ontology Based System for Knowledge Profile Management: A Case Study in the Electric Sector. In: Alor-hernández, G. and Valencia-García, R. (eds.), Current Trends on KnowledgeBased Systems, pp. 302 (2017)

25. Singhal, P., Mittalet, M. L., Agarwal, G.: Supply chain risk management: review, classification and future research directions. Int. J. Bus. Sci. Appl. Manag. 6(3), pp. 15-42 (2011)

26. Tummala, R., Schoenherr, T.: Assessing and managing risks using the Supply Chain Risk Management Process (SCRMP). Supply Chain Manag. An Int. J. 16, pp. 474-483 (2011)

27. Wee, H. M., Blos, M. F., Yanget, W. H.: Risk Management in Logistics. In: Handbook on Decision Making. Springer Berlin Heidelberg, pp. 285-305 (2012)

28. Yossi, R., Kenett, R. S., Pike, R.: Operational risk management: an overview. In: Kenett, R. S., Yossi, R. (eds.) Operational Risk Management. A practical approach to intelligent data analysis, pp. 327 (2011) 